\title{
Oxalic Acid Regeneration of Ceramic Filter Medium Used in the Dewatering of Iron Ore
}

\author{
Riina Salmimies, ${ }^{1}$ Juha Kallas, ${ }^{2}$ Bjarne Ekberg, ${ }^{3}$ and Antti Häkkinen1 \\ ${ }^{1}$ LUT Chemistry, Lappeenranta University of Technology, Skinnarilankatu 34, 53850 Lappeenranta, Finland \\ ${ }^{2}$ Laboratory of Inorganic Materials, Tallinn University of Technology, Ehitajate Tee 5, 19086 Tallinn, Estonia \\ ${ }^{3}$ Outotec (Filters) Oy, Urusvuorenkatu 5, 20630 Turku, Finland
}

Correspondence should be addressed to Riina Salmimies, riina.salmimies@lut.fi

Received 17 September 2012; Accepted 23 October 2012

Academic Editors: J. Lobato and A. Szymczyk

Copyright (c) 2012 Riina Salmimies et al. This is an open access article distributed under the Creative Commons Attribution License, which permits unrestricted use, distribution, and reproduction in any medium, provided the original work is properly cited.

The regeneration of the ceramic filter medium in the dewatering of iron ore enables the use of the medium for much longer periods in comparison to traditional filter cloths. The regeneration is commonly a combination of several techniques, of which one is the acid washing of the medium. Despite being effective against iron oxides, the phenomena related to the acid washing of the ceramic filter medium with oxalic acid have so far been less extensively published. The aim of this study was to investigate the dissolution of iron oxide particles from the surface of the filter medium and the consequent changes in the performance and in the structure of the medium. The dissolution of the particles was found to exhibit some kind of a steady state dependent on temperature but not so much on the acid concentration. Changes in permeability as well as in pore size were found to take place even after the dissolution of the particles had ceased.

\section{Introduction}

The final dewatering of a magnetite concentrate can be performed with ceramic capillary action disc filters. During operation, magnetite particles are adhered to the surface of the filter medium causing the decline of filtrate flux. The ceramic filter medium, however, is robust enough to withstand both mechanical and chemical regeneration, and, consequently, the performance of the filter medium can be restored.

The regeneration of the ceramic filter medium in capillary action disc filters incorporates several operations: (1) backwashing, (2) ultrasonic cleaning, and (3) acid regeneration. In iron ore applications, oxalic acid can be used for the regeneration as it has been shown to efficiently dissolve iron oxides [1-9].

Although the regeneration of ceramic membranes fouled by oxide particles has been receiving an increasing attention in cross flow filtration [10-13], published research on the regeneration of the ceramic membrane used for the dewatering of mineral concentrates is scarce. Even the fundamental effects of oxalic acid regeneration, currently used for several ceramic disc filters in iron ore dewatering, on the filter medium are fairly unknown and make it challenging to develop the regeneration process. The further development of the process, however, requires a deeper understanding of the phenomena underlying the acid treatment of the filter medium.

The aim of this study was to provide more insight into the dissolution of particles during the regeneration and into what are the actual changes in the filter medium as a result of the regeneration. The experiments were done with samples from a full scale dewatering process so to have the samples represent a real case where regeneration is needed.

\section{Methods}

2.1. Regeneration Experiments. Samples for the regeneration were received from a full scale magnetite dewatering process where the filter elements had been in use for 3 to 5 years. The samples of the filter media were characterized with Xray diffraction and scanning electron microscopy, of which the details and results have been presented elsewhere [14]. Samples for the experiments done here were chosen so 
to only have magnetite as an extraneous compound, to eliminate the effect of any other chemical species on the dissolution of magnetite from the surface of the samples.

The ceramic samples were regenerated using oxalic acid at concentrations of $0.08,0.33$, and $0.60 \mathrm{~mol} / \mathrm{L}$, corresponding roughly to $1,4.5$, and $7 \mathrm{wt} \%$, respectively. All solutions were prepared from a solid proanalysis grade oxalic acid dihydrate from Merck. Ultrapure water was used to eliminate any impurities. The regeneration was done at three different temperatures: 15,35 , and $50^{\circ} \mathrm{C}$. The regeneration was done in $0.6 \mathrm{~L}$ beakers where the solutions, $0.5 \mathrm{~L}$ in volume, were thermostated to the desired temperatures under magnetic mixing. A blank sample was drawn of each beaker before introducing the ceramic samples into the beakers. During the regeneration samples of the mother liquour were taken at regular intervals until reaching a total regeneration time of $12 \mathrm{~h}$. The extracted sample volume was roughly $3 \mathrm{~mL}$ with a total volume of solution removed from the system during the regeneration being roughly $40 \mathrm{~mL}$. This accounts for roughly $8 \%$ of the initial total volume of the solution. The samples were drawn with a syringe and filtered with a syringe filter, with a pore size of $0.25 \mu \mathrm{m}$, to remove any solid particles. Finally, the samples were diluted three times with 10 vol\% $\mathrm{HNO}_{3}$ to prevent the precipitation of the soluble Fe.

2.2. Dissolution of $\mathrm{Fe}_{3} \mathrm{O}_{4}$. The $\mathrm{Fe}$ concentration of the mother liquour was determined with flame AAS using a Thermo Scientific iCE 3000 AA spectrometer. The calibration standards were $0.5,1.5,3.0$, and $5.0 \mathrm{mg} / \mathrm{L}$ and were prepared in $10 \mathrm{vol} \% \mathrm{HNO}_{3}$ to mimic the matrix of the samples drawn from the beakers. The samples were diluted with $10 \mathrm{vol} \% \mathrm{HNO}_{3}$ to yield an absorbance fit for the calibration range.

In addition to analyzing the concentration of dissolved Fe from the mother liquour, an imaging with a JEOL JSM5800 scanning electron microscope (SEM) was performed to investigate if any iron oxide particles were still present on the surface of the filter medium. The SEM was operated in backscatter mode with an acceleration voltage of $10 \mathrm{keV}$. No coating was used.

2.3. Permeability. The water flux was measured with a pressure of 0.5 bar for $200 \mathrm{~s}$ with data recorded every $1 \mathrm{~s}$. The data was then averaged to yield a value for the permeability of the sample. The equipment for measuring the permeability consisted of a feed vessel, a pump, a pressure control unit, and housing for the sample (Figure 1).

The permeability, or the water flux in $\mathrm{L} /\left(\mathrm{m}^{2} \mathrm{~h}\right.$ bar $)$, was determined every three hours with the exception of determining it at $t=1 \mathrm{~h}$ and $t=3 \mathrm{~h}$ at the beginning of the experiments. The circular measuring area was roughly $46 \mathrm{~mm}$; that is, the whole surface of the sample was used in the measurement.

2.4. Pore Size Distribution. The pore size distributions were determined using a PMI Advanced Capillary Flow Porometer. The principle of the porometer is fairly simple: the sample is inserted into a sealed chamber, pressure is increased, and the flow of gas through the sample is measured. Measurements are done with a dry and a wet sample yielding the cumulative flow versus time curves for both to calculate the flow corresponding to each pore diameter. The calculation of the pore diameter is based on (1)

$$
p=\frac{4 \mu_{l / g} \cos \Theta}{D},
$$

where $p$ is the differential pressure, $\mu_{l / g}$ is the surface tension of the wetting liquid, $\Theta$ is the contact angle between the liquid and the solid, and $D$ is the pore diameter (SI units). The wetting liquid is assumed to be an ideal wetting agent with a contact angle of $0^{\circ}$ (or 0 rad to be exact) making $\cos \Theta$ equal to 1 . Ultrapure water was used as the wetting liquid here. Although ultrapure water may not be an ideal wetting liquid, it was the best choice in this case, as contamination of the samples and of the regeneration system could have been resulted if was used another liquid.

The bubble point pressure is the point at which the largest pores are emptied from the wetting liquid and gas starts to flow through the sample. At pressures below the bubble point, the wet sample does not allow gas to flow through. Whereas visual bubble point detection is common, here the detection of the bubble point is based on an F/PT factor (or more accurately the $F /(\Delta P / \Delta T)$ ). $F$ stands for the bubble flow, $P$ for pressure, and $T$ for time. The studied sample is inserted into the chamber to which air then starts to flow at a rate set as the bubble flow. At pressures below the bubble point, no flow occurs through the sample and the change in pressure correlates with the change in time. Before reaching the bubble point pressure, the $F / P T$ factor remains constant after which a change, commonly a sharp increase, in the factor is observed at the bubble point pressure.

The pore size distribution is determined as the percentage of flow resulting from each pore diameter. The cumulative percentage is calculated by dividing the wet flow with the dry flow and multiplying by a hundred. The differential percentage is then the difference between two consecutive cumulative values.

The pore size distributions were determined by using a compression pressure of $4 \mathrm{bar}$ and a measuring range from 0.5 to 4 bar. The $F / P T$ factor was 50 and the bubble flow was $27 \mathrm{~cm}^{3} / \mathrm{min}$. The pressure and flow increments were 3 and 0.25 counts, respectively. The F/PT factor and the bubble flow are parameters affecting the detection of the bubble point pressure and the increments are those determining the number of steps at a given pressure range, that is, the number of data points. The circular measuring area had a diameter of roughly $35 \mathrm{~mm}$; that is, the whole surface of the sample was not used in the measurement. The pore size distribution was determined every three hours, like the permeability, after the sample had been dried in an oven over night.

\section{Results and Discussion}

3.1. Dissolution of $\mathrm{Fe}_{3} \mathrm{O}_{4}$. The final concentration of dissolved Fe seemed to be temperature dependent as, in the whole data set, the dissolution curves showed slight grouping 


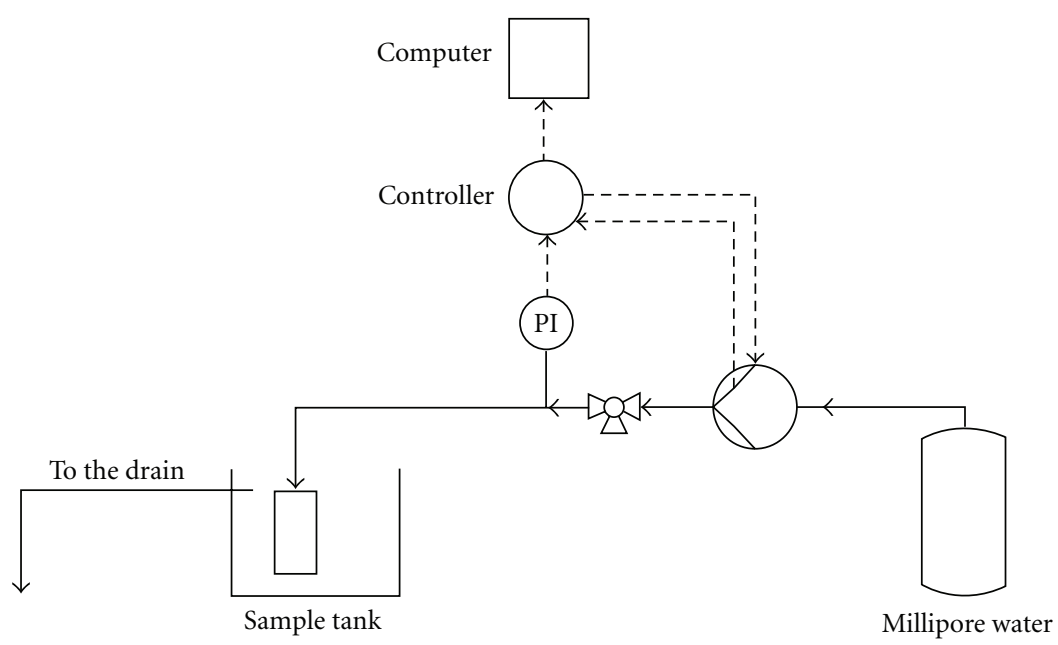

FIGURE 1: Equipment for measuring the water permeability of the samples.

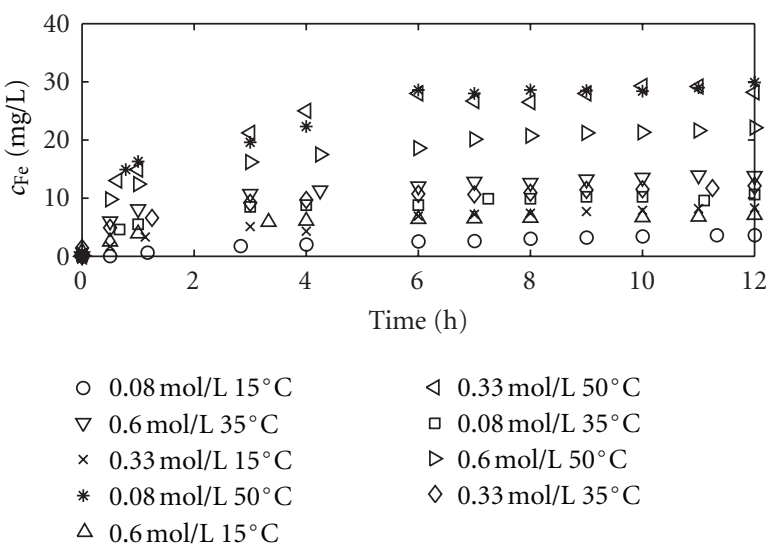

FIGURE 2: The concentration of dissolved Fe in the mother liqueur during the regeneration with oxalic acid at different concentrations of acid and at different temperatures.

according to temperature (Figure 2). The lowest concentration of dissolved $\mathrm{Fe}$ was obtained with $0.08 \mathrm{~mol} / \mathrm{L}$ oxalic acid at $15^{\circ} \mathrm{C}$. The dependency of the final concentration of dissolved $\mathrm{Fe}$ roughly followed the same trends observed in earlier studies for free particles [8]. The influence of the acid concentration was, however, questionable as the results did not show similar grouping according to the acid concentration as they did according to the temperature.

The highest concentration of dissolved Fe was observed at $50^{\circ} \mathrm{C}$ and the lowest at $15^{\circ} \mathrm{C}$ (Figure $3(\mathrm{a})$ ). This observation was rather interesting as the initial hypothesis was that complete dissolution of the Fe particles would take place when the regeneration was extended for a long period of time. Here, the concentration of dissolved Fe showed signs of steady state already after roughly 3-6 hours. If complete dissolution of the Fe particles, adhered to the surface of the filter medium, indeed took place, the final concentration of Fe should not have shown a temperature dependency but rather random scattering. Scattering of the data could have been a result of differences in the samples but is, in this case, unlikely because the data seemed to group distinctively

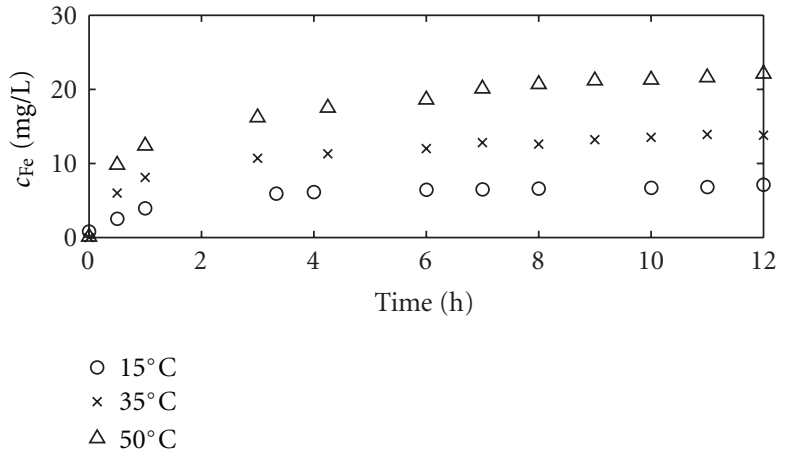

(a)

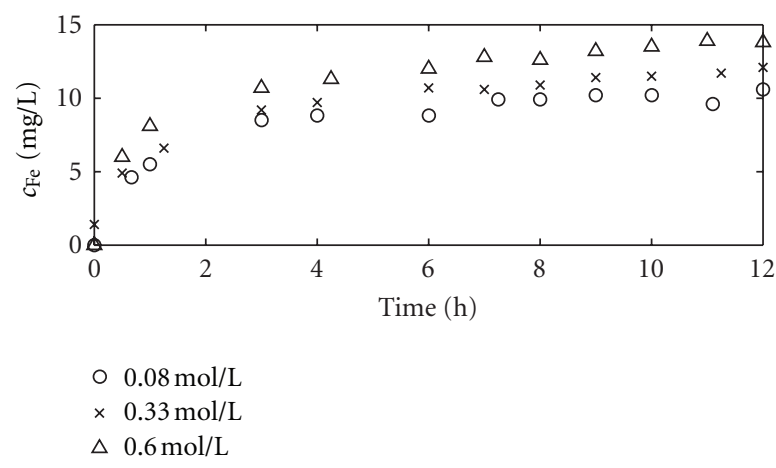

(b)

Figure 3: The individual effects of temperature (a) and acid concentration (b) on the concentration of dissolved Fe during the regeneration of the ceramic filter medium. The acid concentration in (a) was $0.60 \mathrm{~mol} / \mathrm{L}$ and the temperature in (b) was $35^{\circ} \mathrm{C}$.

according to the different temperatures instead of scattering randomly. When dissolving in $50^{\circ} \mathrm{C}$, acid concentrations of 0.08 and $0.33 \mathrm{~mol} / \mathrm{L}$ yielded roughly the same final concentration of dissolved Fe whereas $0.60 \mathrm{~mol} / \mathrm{L}$ showed a much lower concentration. This difference could simply be due to initial differences in the quantity of magnetite in the samples: samples regenerated in the two lower acid concentrations were more similar to each other than the one regenerated at 


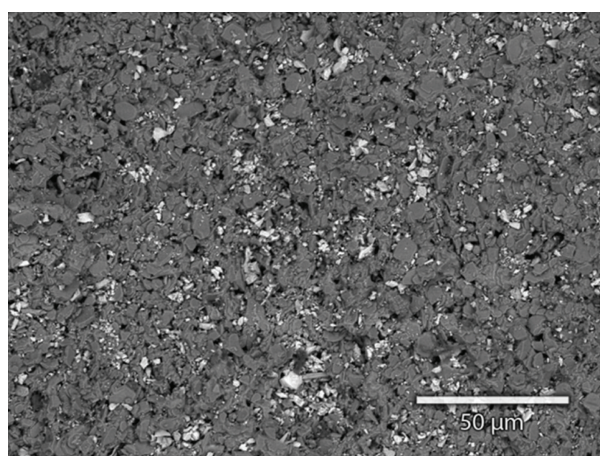

(a)

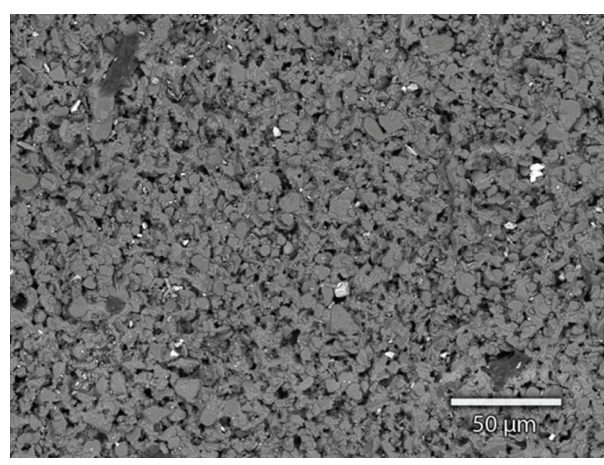

(b)

Figure 4: SEM image showing particles left on the surface and between the alumina grains: (a) $0.08 \mathrm{~mol} / \mathrm{L}$ oxalic acid at $15^{\circ} \mathrm{C}$ and (b) $0.60 \mathrm{~mol} / \mathrm{L}$ oxalic acid at $50^{\circ} \mathrm{C}$.

the highest acid concentration. Dissolution at $35^{\circ} \mathrm{C}$ yielded three almost identical dissolution curves (Figure 3(b)), where the effect of acid concentration could, however, still be seen. The highest acid concentration resulted in the highest concentration of dissolved Fe.

The kinetics of dissolution seemed to be affected by temperature as well: higher rates were observed when dissolving at a higher temperature as indicated by the slopes of the dissolution curves at the early stages of dissolution. Similar indication was found in the experiments done at different acid concentrations but the effect was again less pronounced than for the temperature.

As already previously mentioned, the samples were selected so to be as similar as possible in their chemical composition. Inspection of the surface with SEM showed that some small particles were still left on the surface of the filter medium and between the alumina grains (Figure 4).

Where lower quantities of dissolved $\mathrm{Fe}$ were obtained during the regeneration, more $\mathrm{Fe}_{3} \mathrm{O}_{4}$ particles were found on the surface, too. The observation further confirmed that the dissolution of the particles was dependent on the solution conditions.

\subsection{Changes in the Permeability and Pore Size Distribution of} the Filter Medium. Increased permeability was observed as a result of the regeneration, as was expected (Figure 5).

Whereas most of the magnetite particles were dissolved already during the first three hours of regeneration, the permeability still continued to increase until reaching a steady state between 6 and $12 \mathrm{~h}$. As the dissolution of particles from the surface had stopped, possible structural changes within the filter medium could be a cause for the observation. Dissolution of any components within the filter medium could, however, most likely not be observed as the liquid which had penetrated into the structure of the filter medium during the regeneration cannot flow outwards without external pressure.

According to the experiments, the final permeability after regeneration was between 5000 and $7000 \mathrm{~L} /\left(\mathrm{m}^{2} \mathrm{~h}\right.$ bar $)$. These values roughly correspond to full regeneration of the filter medium. Whereas the highest concentrations of dissolved Fe were observed at the highest temperature, $50^{\circ} \mathrm{C}$, the

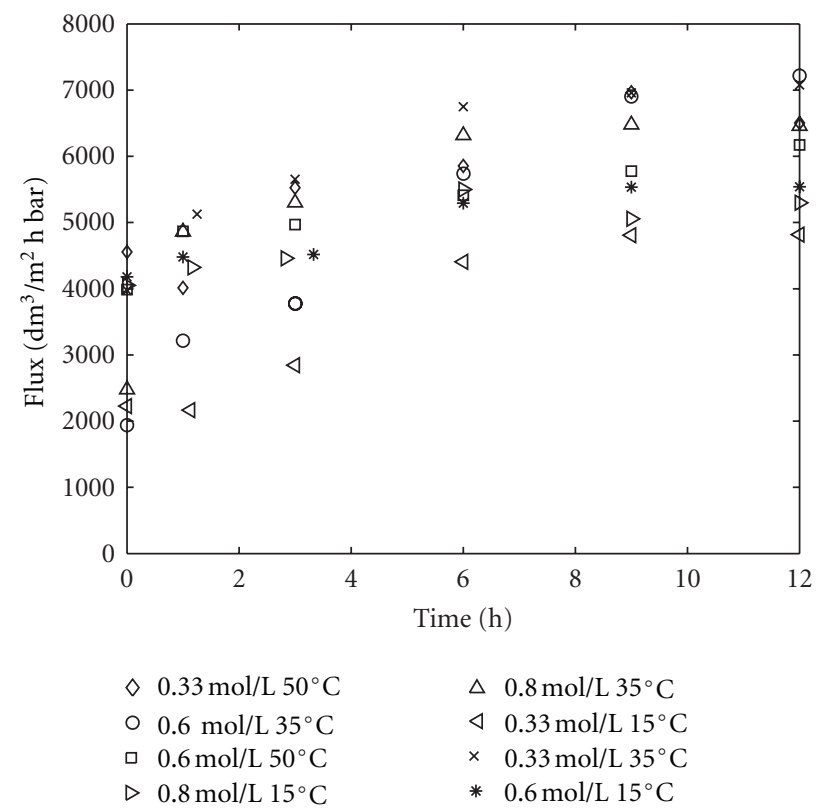

Figure 5: Permeability of the filter medium samples during the regeneration with oxalic acid. The permeability was measured at 0.5 bar pressure.

highest final permeabilities were observed at $35^{\circ} \mathrm{C}$. This suggests that the dissolution of surface particles is not the only phenomenon determining the regeneration result. In general, the final permeability seemed to be dependent on the acid concentration, as the highest acid concentrations yielded the highest permeabilities at each temperature. Some discrepancies were, however, observed, for example, at $15^{\circ} \mathrm{C}$ $0.08 \mathrm{~mol} / \mathrm{L}$ oxalic acid resulted in a higher permeability than $0.33 \mathrm{~mol} / \mathrm{L}$. Some of the differences could have been due to inherent differences in the initial permeabilities of the samples.

All the data for the pore size distributions are not presented here but only an example of the experiments done at $35^{\circ} \mathrm{C}$. Similar trends were observed in all the experiments. The changes in the pore size distribution described the changes in the structure of the filter medium more accurately than the permeability. Changes in the bubble point did not 


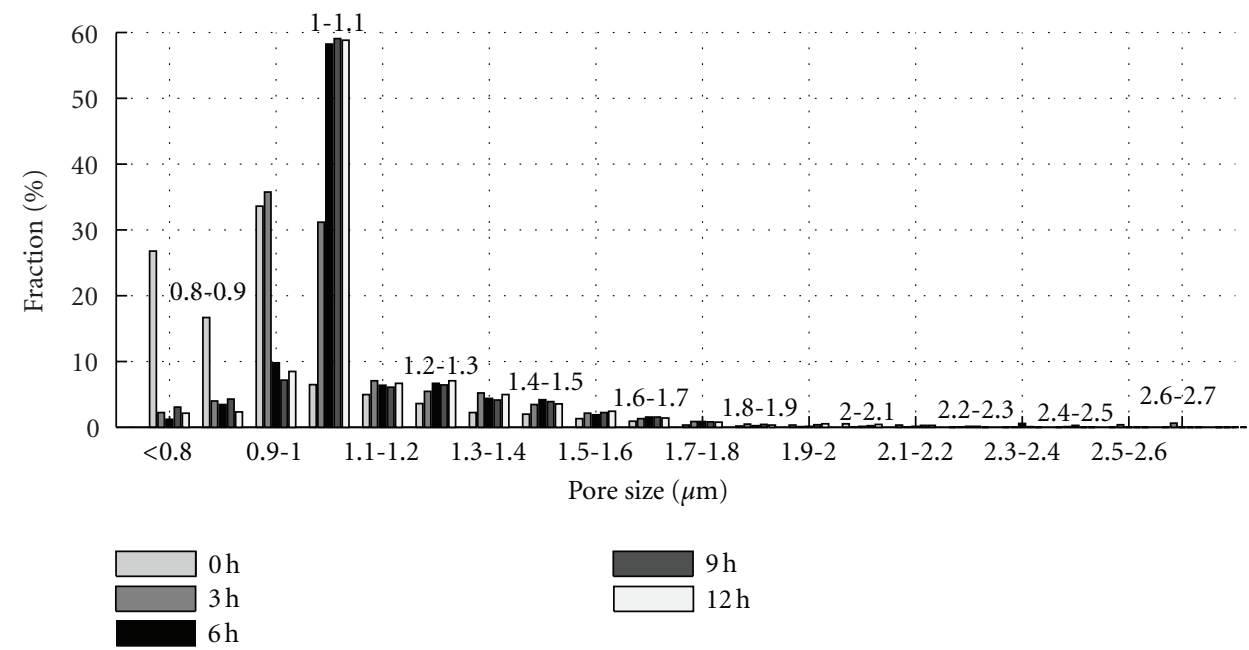

FIgURE 6: Changes in the pore size distribution of the filter medium during the regeneration with 0.33 oxalic acid at $35^{\circ} \mathrm{C}$.

TABLE 1: The bubble point pressure, the corresponding bubble point pore diameter, and the median flow pore diameter for the ceramic samples before, during, and after the regeneration with oxalic acid at $35^{\circ} \mathrm{C}$.

\begin{tabular}{lccc}
\hline$t(\mathrm{~h})$ & $\mathrm{BPP}^{1}(\mathrm{bar})$ & $\mathrm{BPPD}^{2}(\mu \mathrm{m})$ & $\mathrm{MFPS}^{3}(\mu \mathrm{m})$ \\
\hline & & $0.08 \mathrm{~mol} / \mathrm{L}$ & \\
0 & 1.33 & 1.55 & 0.63 \\
3 & 0.75 & 2.73 & 0.68 \\
6 & 0.74 & 2.79 & 0.70 \\
9 & 0.73 & 2.83 & 0.70 \\
12 & 0.74 & 2.78 & 0.69 \\
\hline & & $0.33 \mathrm{~mol} / \mathrm{L}$ & \\
0 & 1.34 & 1.54 & 0.65 \\
3 & 1.07 & 1.92 & 0.72 \\
6 & 1.17 & 1.76 & 0.74 \\
9 & 1.21 & 1.57 & 0.74 \\
12 & 1.31 & 1.37 & 0.74 \\
\hline & & 1.40 & 0.69 \\
0 & 1.51 & 1.42 & 0.75 \\
3 & 1.48 & 1.42 & 0.80 \\
6 & 1.45 & 1.43 & 0.81 \\
9 & 1.45 & & 0.81 \\
12 & 1.44 & &
\end{tabular}

${ }^{1}$ Bubble point pressure, ${ }^{2}$ bubble point pore diameter, ${ }^{3}$ mean flow pore diameter.

represent the changes in the filter medium too well, as the bubble point did not seem to change too much in all the samples (Table 1).

Some of the samples did exhibit significant decrease in the bubble point pressure but this was not the case for all of the samples which might suggest that the individual observations were most likely due to inherent differences in the samples instead of a trend. As previously mentioned the bubble point pressure only describes the size of the largest pores and might thus not be the most suitable tool to estimate the regeneration of the filter medium. The pore size distributions did, however, show significant changes in the structure of the filter medium (Figure 6).

The results showed that the fraction of the largest pores did not increase significantly which most likely explains why large changes in the bubble point pressure were not observed. The results did, however, also show that the fraction of pores in the range of $1-1.1 \mu \mathrm{m}$ increased markedly as a result of the regeneration. In turn, the fraction of smaller pores, below $1.0 \mu \mathrm{m}$, decreased notably. As described earlier, the samples were wetted with ultrapure water for the porometer which could be a source for error in the calculations for the pore size distribution. However, every sample was treated in the same way and changes in the pore size distribution can be reported although absolute values might contain a small error. Distinction between surface and inner structure changes cannot be made based on the pore size distributions as the measurement only accounts for the smallest diameter of a pore whether it is the pore's surface diameter or a narrow constriction within the medium.

The regeneration of the filter medium in a large scale process is based on the combination of several actions. The use of ultrasound could significantly enhance the dissolution rate and the consequent regeneration rate of the filter medium. Ultrasound was, however, not considered here as the aim was to investigate the basic underlying phenomena of the acid regeneration and including ultrasound could have made it more difficult to interpret the results of the chemical dissolution experiments.

\section{Conclusions}

The dissolution of $\mathrm{Fe}_{3} \mathrm{O}_{4}$ particles and the consequent changes in the permeability and the pore size distribution of the filter medium samples were studied by regenerating the samples in oxalic acid at different temperatures.

The temperature dependency of dissolution, observed here, could indicate that the dissolution of the particles is affected by some sort of equilibrium. This observation seems 
very interesting as the solubility limit for $\mathrm{Fe}_{3} \mathrm{O}_{4}$ particles is much higher than the concentrations obtained here.

Higher permeabilities were achieved at higher acid concentrations, although a direct correlation between the acid concentration and the dissolution of the particles was not found. The lowest permeabilities were obtained at the lowest regeneration temperatures, and here the removal of $\mathrm{Fe}_{3} \mathrm{O}_{4}$ from the surface correlated with permeability restoration: if the particles are not removed, the pores remain blinded. Further increase was, however, observed even after the dissolution of $\mathrm{Fe}_{3} \mathrm{O}_{4}$ particles had come to an end which suggests that something else besides the dissolution of surface particles also took place during the regeneration. No aluminium was, however, found in the liquid phase suggesting that the filter medium itself had not been dissolved.

The changes in the pore size distribution indicated the decrease of the fraction of small pores and a consequent increase in the number of slightly larger pores. Changes in the bubble point pressures were not conclusive indicating that the bubble point pressure might not be the best tool to evaluate the changes in the pore structure.

\section{Acknowledgments}

The authors would like to acknowledge the Graduate School of Chemical Engineering for funding this research. In addition, the authors are grateful to Outotec (Filters) Oy for providing the samples of the ceramic filter medium which were vital in making possible the integration between academic research and industrial relevance.

\section{References}

[1] M. A. Blesa, H. A. Marinovich, E. C. Baumgartner, and A. J. G. Maroto, "Mechanism of dissolution of magnetite by oxalic acid-ferrous ion solutions," Inorganic Chemistry, vol. 26, no. 22, pp. 3713-3717, 1987.

[2] R. M. Cornell and P. W. Schindler, "Photochemical dissolution of goethite in acid/oxalate solution," Clays and Clay Minerals, vol. 35, no. 5, pp. 347-352, 1987.

[3] M. Taxiarchou, D. Panias, I. Douni, I. Paspaliaris, and A. Kontopoulos, "Dissolution of hematite in acidic oxalate solutions," Hydrometallurgy, vol. 44, no. 3, pp. 287-299, 1997.

[4] G. J. Houben, "Iron oxide incrustations in wells. Part 2: chemical dissolution and modeling," Applied Geochemistry, vol. 18, no. 6, pp. 941-954, 2003.

[5] S. K. Mandal and P. C. Banerjee, "Iron leaching from China clay with oxalic acid: effect of different physico-chemical parameters," International Journal of Mineral Processing, vol. 74, no. 1-4, pp. 263-270, 2004.

[6] S. O. Lee, T. Tran, Y. Y. Park, S. J. Kim, and M. J. Kim, "Study on the kinetics of iron oxide leaching by oxalic acid," International Journal of Mineral Processing, vol. 80, no. 2-4, pp. 144-152, 2006.

[7] S. O. Lee, T. Tran, B. H. Jung, S. J. Kim, and M. J. Kim, "Dissolution of iron oxide using oxalic acid," Hydrometallurgy, vol. 87, no. 3-4, pp. 91-99, 2007.

[8] R. Salmimies, M. Mannila, J. Kallas, and A. Häkkinen, "Acidic dissolution of magnetite: experimental study on the effects of acid concentration and temperature," Clays and Clay Minerals, vol. 59, no. 2, pp. 136-146, 2011.

[9] R. Salmimies, M. Mannila, J. Kallas, and A. Häkkinen, "Acidic dissolution of hematite: kinetic and thermodynamic investigations with oxalic acid," International Journal of Mineral Processing, vol. 110-111, pp. 121-125, 2012.

[10] Y. Zhao, J. Zhong, H. Li, N. Xu, and J. Shi, "Fouling and regeneration of ceramic microfiltration membranes in processing acid wastewater containing fine $\mathrm{TiO}_{2}$ particles," Journal of Membrane Science, vol. 208, no. 1-2, pp. 331-341, 2002.

[11] M. Gryta, "Effect of iron oxides scaling on the MD process performance," Desalination, vol. 216, no. 1-3, pp. 88-102, 2007.

[12] H. Yamamura, S. Chae, K. Kimura, and Y. Watanabe, "Transition in fouling mechanism in microfiltration of a surface water," Water Research, vol. 41, no. 17, pp. 3812-3822, 2007.

[13] T. Quadt and E. Schmidt, "Membranes: optimising the regeneration of ceramic membranes," Filtration and Separation, vol. 48 , no. 6, pp. 26-28, 2011.

[14] R. Salmimies, A. Häkkinen, J. Kallas, B. Ekberg, J. P. Andreassen, and R. Beck, "Characterisation of long-term scaling effects of ceramic filter media used in the dewatering of iron ore," in Proceedings of the Iron Ore 2011, AusIMM, Perth, Australia, 2011. 

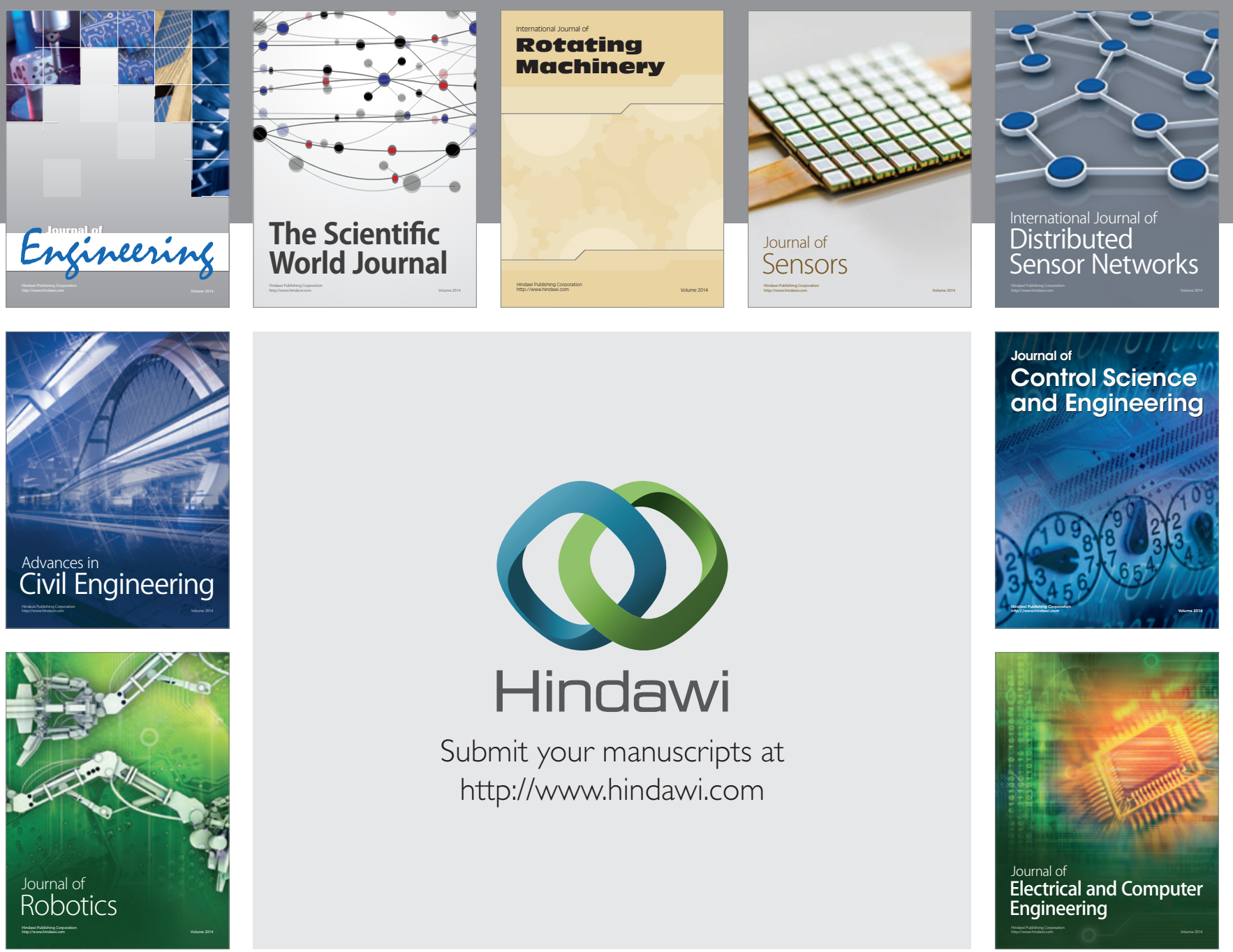

Submit your manuscripts at

http://www.hindawi.com
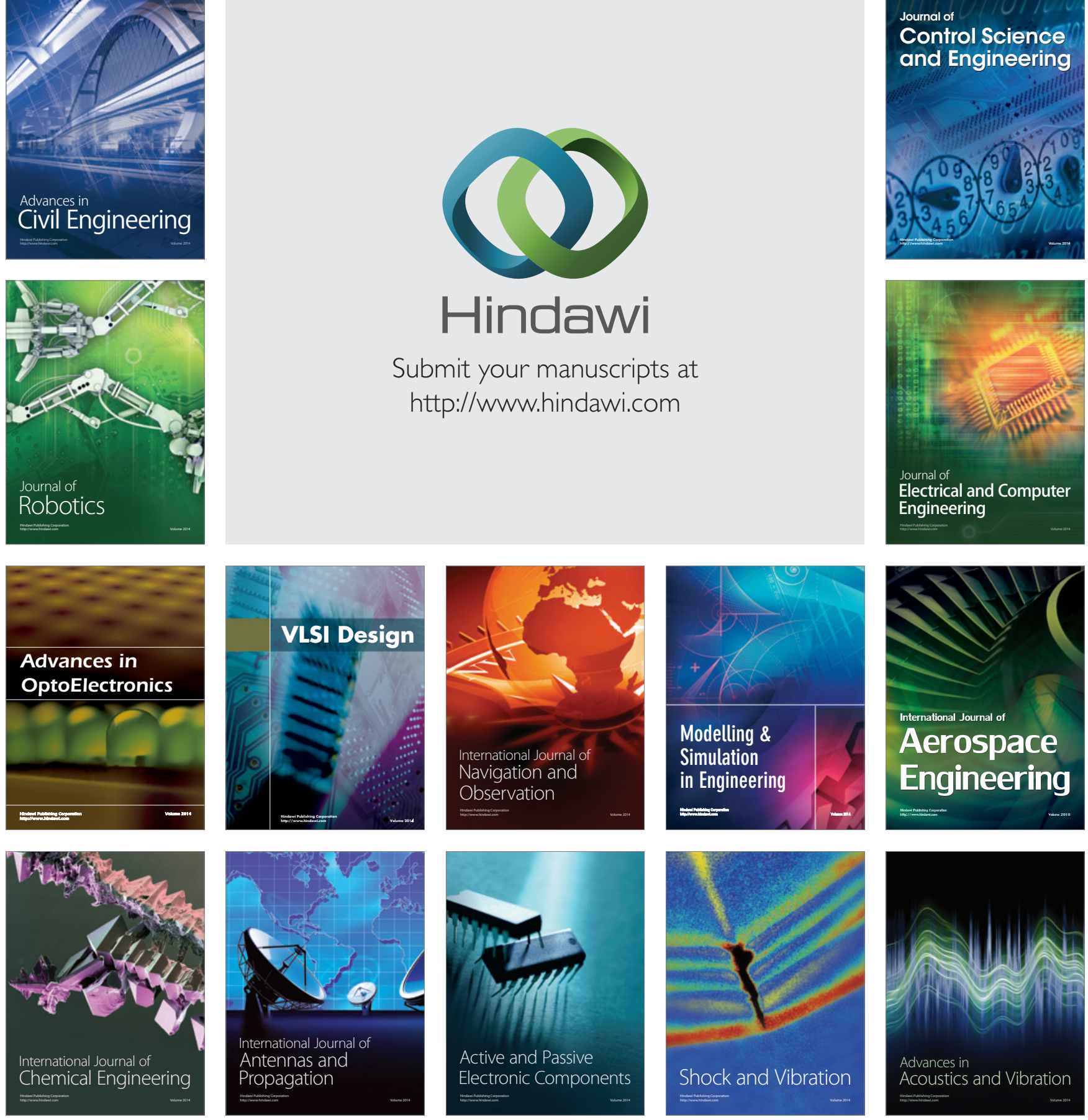